\section{Probing RNA Structures with Hydroxyl Radicals}

Iron(II)-EDTA is the principal reagent whereby one can conveniently generate hydroxyl radicals to promote cleavage of RNA at nucleotide resolution. In this unit, the Basic Protocol describes the simplest cleavage conditions, whereby free radicals originate from solvated molecular oxygen, while the Alternate Protocol outlines a more elaborate procedure commonly used to generate free radicals from hydrogen peroxide added to solution. In both procedures, Fe(II)-EDTA is added to solution mixtures containing end-labeled RNA, either alone or equilibrated with another ligand (e.g., protein), to allow for oxidative strand scission of the RNA chain under neutral buffer conditions. A similar cleavage pattern is observed using either method.

CAUTION: When working with radioactivity, take appropriate precautions to avoid contamination of the experimenter and the surroundings. Carry out the experiment and dispose of wastes in an appropriately designated area, following the guidelines provided by the local radiation safety officer.

NOTE: Experiments involving RNA require careful precautions to prevent contamination and RNA degradation (see APPENDIX 2A).

NOTE: All reagents should be $\geq 99 \%$ purity. All solutions must be prepared fresh in sterile water immediately before use and should be discarded thereafter.

\section{STRAND SCISSION OF RNA USING O2-DERIVED FREE RADICALS}

For strand scission of RNA using free radicals derived from solvated oxygen, $5^{\prime}$ - or 3'-end-labeled RNA is equilibrated under the desired buffer or ligand-binding conditions. The Fe(II)-EDTA mixture and a suitable reducing agent are added to the RNA mixture to initiate the strand scission reaction and, after a 1- to 2-hr incubation, the free-radical reaction is quenched. The RNA is then directly processed alongside sequencing standards on a denaturing polyacrylamide gel to resolve the cleavage products.

\section{Materials}

End-labeled RNA with a specific activity $\geq 2 \times 10^{6} \mathrm{dpm} / \mathrm{pmol}$ (UNIT 6.1)

Appropriate buffers and RNA-binding ligands (see Critical Parameters)

1,4-Dithiothreitol (DTT; store at $-20^{\circ} \mathrm{C}$ )

$\left(\mathrm{NH}_{4}\right)_{2} \mathrm{Fe}(\mathrm{III})\left(\mathrm{SO}_{4}\right)_{2} \cdot 6 \mathrm{H}_{2} \mathrm{O}$ powder (store at room temperature)

$200 \mathrm{mM} \mathrm{Na} 2$ EDTA, pH 8.0 (APPENDIX 2A), prepared in sterile water

$100 \mathrm{mM}$ thiourea in sterile water (store at $4^{\circ} \mathrm{C}$ )

$2 \times$ urea loading buffer (APPENDIX 2A)

T1 nuclease digest and alkaline hydrolysis of end-labeled RNA (UNIT 6.1)

Distilled, deionized water, autoclaved before use

0.5 - and $1.5-\mathrm{mL}$ polypropylene microcentrifuge tubes, sterile

RNase-free micropipettors and tips

Water bath or suitable incubator

Radioanalytic detection instrument or autoradiography film

Additional reagents and equipment for denaturing polyacrylamide gel electrophoresis (PAGE; see APPENDIX 3B)
UNIT 6.5

BASIC

PROTOCOL

Chemical and

Enzymatic Probes

for Nucleic Acid

Structure 
1. Combine 0.1 pmol end-labeled RNA, the buffer components (e.g., buffers or simple salts), any additional RNA-binding ligands (e.g., proteins), and water to a total volume of $8 \mu \mathrm{L}$ in a 0.5 -mL polypropylene tube. Prepare an identical tube as a control. Incubate the mixture at the desired temperature until equilibrium is achieved.

The buffers, incubation temperature, and the time required to achieve equilibration of the folded RNA with any additional ligands must be determined independently by the investigator (see Critical Parameters).

2. During equilibration, dissolve $7.7 \mathrm{mg}$ DTT in $1 \mathrm{~mL}$ sterile water (final $50 \mathrm{mM}$ ) in a 1.5-mL microcentrifuge tube.

This solution should be made fresh immediately before use.

3. Add $39.4 \mathrm{mg}\left(\mathrm{NH}_{4}\right)_{2} \mathrm{Fe}(\mathrm{II})\left(\mathrm{SO}_{4}\right)_{2} \cdot 6 \mathrm{H}_{2} \mathrm{O}$ to a sterile microcentrifuge tube and store in the dark until use.

4. Once the RNA solution has achieved equilibrium, prepare the Fe(II)-EDTA solution for immediate addition to the RNA solution. Add $1 \mathrm{~mL}$ sterile water to the tube containing $\left(\mathrm{NH}_{4}\right)_{2} \mathrm{Fe}(\mathrm{II})\left(\mathrm{SO}_{4}\right)_{2} \cdot 6 \mathrm{H}_{2} \mathrm{O}$ (final $100 \mathrm{mM}$ ) and vortex well to completely dissolve. In a separate polypropylene microcentrifuge tube, combine $10 \mu \mathrm{L}$ of this solution with $10 \mu \mathrm{L}$ of $200 \mathrm{mM} \mathrm{Na}_{2}$ EDTA solution and $80 \mu \mathrm{L}$ sterile water, yielding $10 \mathrm{mM}$ Fe(II) and $20 \mathrm{mM}$ EDTA. Vortex well.

5. Immediately add $1 \mu \mathrm{L} \mathrm{Fe(II)-EDTA} \mathrm{solution} \mathrm{and} 1 \mu \mathrm{L}$ of $50 \mathrm{mM}$ DTT solution to the RNA mixture to yield a final volume of $10 \mu \mathrm{L}$ containing $1 \mathrm{mM} \mathrm{Fe}(\mathrm{II}), 2 \mathrm{mM}$ EDTA, and $5 \mathrm{mM}$ DTT. Add $2 \mu \mathrm{L}$ sterile water to the control tube.

The remaining DTT and $\mathrm{Fe}(I I)-E D T A$ solutions should be discarded following their use.

6. Incubate the reaction mixture for 1 to $2 \mathrm{hr}$ at the desired temperature.

The indicated time period is sufficient to generate a partial digest pattern of end-labeled $R N A$ under single-hit conditions (see Commentary). The cleavage reaction displays a modest temperature dependence; nevertheless, suitable cleavage profiles have been obtained for reactions performed at temperatures ranging from $0^{\circ}$ to $50^{\circ} \mathrm{C}$ (Celander and Cech, 1991).

7. Add $1 \mu \mathrm{L}$ of $100 \mathrm{mM}$ thiourea to quench the free radical reaction. Also add thiourea to the control tube.

8. Add an equal volume of $2 \times$ urea loading buffer to each tube.

If larger reaction volumes are used, the RNA should be precipitated from ethanol before the addition of urea loading buffer.

At this point, the reaction samples can be stored up to several days at $-20^{\circ} \mathrm{C}$.

9. Fractionate the reaction mixture on a denaturing polyacrylamide gel ( $8 \%$ to $20 \%$; APPENDIX $3 B$ ), using a T1 digest and an alkaline hydrolysis of the original end-labeled RNA as a sequencing standard for the free-radical cleavage reactions.

10. Dry the gel and expose it to film by autoradiography or to a phosphor plate for quantitation using a radioanalytic detection instruments. 
This procedure is similar in several details to that described in the Basic Protocol. However, since the free radicals originate from hydrogen peroxide rather than from solvated molecular oxygen, the reaction proceeds at a more rapid pace.

Additional Materials (also see Basic Protocol)

$0.6 \%(\mathrm{w} / \mathrm{w})$ hydrogen peroxide $\left(\mathrm{H}_{2} \mathrm{O}_{2}\right)$ in sterile water, freshly prepared from $30 \%$ (w/w) commercial solution

Sodium ascorbate powder

1. Prepare and equilibrate the RNA mixture as described (see Basic Protocol, step 1) but use a total volume of $7 \mu \mathrm{L}$.

2. During equilibration, dissolve $1.98 \mathrm{mg}$ sodium ascorbate in $1 \mathrm{~mL}$ sterile water (final $10 \mathrm{mM})$.

This solution should be made fresh immediately before use. It may be easier to prepare 10 $m L$ solution.

3. Add $39.4 \mathrm{mg}\left(\mathrm{NH}_{4}\right)_{2} \mathrm{Fe}(\mathrm{II})\left(\mathrm{SO}_{4}\right)_{2} \cdot 6 \mathrm{H}_{2} \mathrm{O}$ to a sterile microcentrifuge tube and store in the dark until use.

4. Once the RNA solution has achieved equilibrium, prepare the Fe(II)-EDTA solution (see Basic Protocol, step 4).

5. Immediately add the following to the reaction mixture (total $10 \mu \mathrm{L}$ ):

$1 \mu \mathrm{L} \mathrm{Fe}(\mathrm{II})-\mathrm{EDTA}$ solution

$1 \mu \mathrm{L} 0.6 \%(w / w) \mathrm{H}_{2} \mathrm{O}_{2}$

$1 \mu \mathrm{L} 10 \mathrm{mM}$ sodium ascorbate.

Add $3 \mu \mathrm{L}$ sterile water to the control tube.

Final reagent concentrations are $1 \mathrm{mM} \mathrm{Fe}(\mathrm{II}), 2 \mathrm{mM} E D T A, 0.06 \% \mathrm{H}_{2} \mathrm{O}_{2}$, and $1 \mathrm{mM}$ sodium ascorbate.

The remaining sodium ascorbate, $\mathrm{H}_{2} \mathrm{O}_{2}$, and $\mathrm{Fe}(\mathrm{II})$-EDTA solutions should be discarded following their use.

6. Incubate the reaction mixture for 1 to $3 \mathrm{~min}$ at the desired temperature.

7. Quench, fractionate, and observe the reaction as described (see Basic Protocol, steps 7 to 10$)$.

\section{COMMENTARY}

\section{Background Information}

The RNA strand scission reaction described here is initiated by a free radical, which originates from the reduction of an oxygen species in solution. The oxidation of the Fe(II)-EDTA reagent provides the source of electrons needed for reduction of molecular oxygen or hydrogen peroxide to form the reactive free radicals. The inclusion of a reducing agent, such as dithiothreitol or ascorbate, allows for the recycling of Fe(III)-EDTA to Fe(II)-EDTA. The formation of free radicals from solvated mo- lecular oxygen can proceed via a hydroperoxide intermediate. The direct employment of a suitable concentration of hydrogen peroxide bypasses the requirement for an initial electron transfer to oxygen to generate the superoxide precursor of the hydroperoxide intermediate, as well as the ensuing bimolecular reactions giving rise to the peroxide. Consequently, the free radical cleavage reaction proceeds more rapidly in the Alternate Protocol than in the Basic Protocol. Before the RNA is loaded onto a denaturing polyacrylamide gel, a free-radical
Chemical and Enzymatic Probes for Nucleic Acid Structure 
scavenger, such as thiourea, is added to quench the highly reactive hydroxyl radicals that are generated during the reaction. These reactions are as follows:

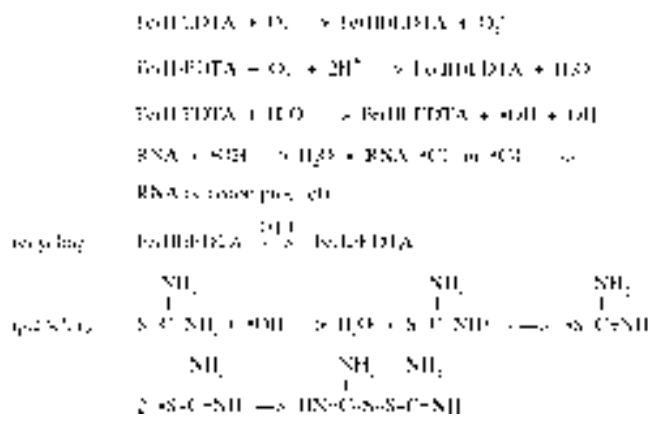

An analysis of nucleic acid products generated by the Fe(II)-EDTA cleavage reagent is consistent with the mechanism of strand scission beginning with hydrogen atom abstraction occurring at the $\mathrm{C}^{\prime}$ ' position of ribose (Hertzberg and Dervan, 1984). Following oxidative damage of the ribose ring, a $\beta$-elimination-like reaction decomposes the ribose ring and directly leads to strand scission of the RNA chain. The $\mathrm{C}^{\prime}$ ' hydrogen atoms are equally accessible on single- and double-stranded forms of RNA; therefore, it is not surprising that free radical-induced cleavage of RNA occurs with little preference for primary sequence or secondary structure (Celander and Cech, 1990). The folding of RNA tertiary structure often results in ribose moieties having different extents of accessibility to solvent. In the case of tRNA ${ }^{\text {Phe }}$ and the group I intron from Tetrahymena thermophila, different regions of the RNA were found to be protected from cleavage by the Fe(II)-EDTA reagent (Latham and Cech, 1989). A striking correlation was found to exist for both RNA molecules in which the ribose positions that were underrepresented in the Fe(II)-EDTA cleavage reactions were found to possess low solvent-accessible surface areas (Latham and Cech, 1989; Cate et al., 1996). Thus, the Fe(II)-EDTA reagent can be used to discriminate solvent inaccessible surfaces within RNA molecules. Such surfaces arise whenever RNA tertiary structure forms a compact structure or through the binding of a ligand (e.g., a protein or an antibiotic drug) to RNA.

The Fe(II)-EDTA cleavage reagent has been used to characterize the folded conformation and folding pathways of several ribozymes, including group I introns (Latham and Cech, 1989; Celander and Cech, 1991;
Heuer et al., 1991), RNase P RNAs (Pan, 1995; Westhof et al., 1996), and the delta virus ribozyme (Rosenstein and Been, 1996). Likewise, RNA regions that are protected by bound ligands have been elucidated in many systems with the use of the Fe(II)-EDTA cleavage reagent (Darsillo and Huber, 1991; Westhof et al., 1996). The chief utility and power of the $\mathrm{Fe}(\mathrm{II})-\mathrm{EDTA}$ cleavage reagent lies in its ability to generate oxidative damage at every ribose moiety along the RNA chain, resulting in a pattern of strand scission with single-nucleotide resolution. Other chemical and enzymatic cleavage reagents commonly used today display primary sequence or secondary structure preference in their cleavage profile, so every nucleotide position along the RNA cannot be simultaneously monitored in a single experiment.

It must be emphasized that the Fe(II)EDTA cleavage reagent protocols described here should only be used to monitor the solvent-accessible surfaces of RNA when folded in solution or when bound by a ligand under conditions of thermodynamic equilibrium. This particular reagent is not well suited to monitor folding transitions that occur on a more rapid scale than free radical formation by $\mathrm{Fe}$ (II)-EDTA. A higher flux of free radical formation is required to monitor the kinetics of RNA conformational changes or protein binding that occur on the millisecond time scale. Radiolysis of water by high-energy $\mathrm{X}$ rays produces hydroxyl radicals and free electrons. Irradiation of solutions by the high-flux "white light" X-ray beam, such as the X-19C at the National Synchrotron Light Source, yields sufficient concentrations of hydroxyl radicals so that cleavage kinetics required for quantitative nuclease protection studies of RNA can be done with exposures as short as 50 msec (Sclavi et al., 1997, 1998). This and similar sources are now available for characterizing conformational changes in RNA on a more rapid time scale.

\section{Critical Parameters}

The successful application of either protocol relies on three critical parameters: (1) the quality of the end labeled RNA, (2) the reduction or elimination of substances from the reaction cocktail that act as free radical scavengers, and (3) the freshness of the $\mathrm{Fe}(\mathrm{II})$ EDTA cleavage reagent and companion reducing agent.
Probing RNA Structures with Hydroxyl Radicals 


\section{RNA quality}

Any chemical modification procedure that generates a degradation product as the principal species requires that the investigator uses RNA of known length. For end-labeled RNA molecules, it is imperative that full-length species are subject to Fe(II)-EDTA cleavage. The reason for this criterion is that end-labeled RNA transcripts that are broken fragments of fulllength molecules may adopt conformations that differ from the population of full-length molecules. Since the Fe(II)-EDTA cleavage reagent cannot discriminate among these different populations of RNA transcripts, two or more different cleavage profiles will be superimposed upon the entire end-labeled RNA population if the RNA is not homogenous. The net result is a pattern of cleavage that is difficult to interpret because it is difficult to relate the cumulative cleavage profile to each RNA population present in the reaction. RNA fragmentation occurs readily through the use of nucleasecontaminated enzymes or by adventitious cleavage of RNA by metal ions in solution. The full-length, end-labeled RNA transcripts can be readily purified from any smaller products using denaturing PAGE (e.g., СPMB UNIT 2.12).

Freshly labeled RNA is also recommended for use in these protocols. The very high specific end-labeling of RNA with ${ }^{32} \mathrm{P}$ (3000 to $6000 \mathrm{Ci} / \mathrm{mmol}$ ) results in molecules that are prone to degradation by either direct or watermediated autoradiolysis over time. A subtle degradation profile begins to emerge following storage of end-labeled RNA molecules for a period of 10 to 14 days at $-20^{\circ} \mathrm{C}$. The degradation pattern would not generally interfere with many studies performed with radiolabeled RNA, yet the intensity of the profile is significant enough to obscure the interpretation of the subtle cleavage profiles generated by $\mathrm{Fe}(\mathrm{II})$ EDTA. Free-radical scavengers can protect the RNA from water-mediated autoradiolysis; however, their inclusion in RNA storage buffers is discouraged because such compounds will interfere with the strand scission reaction promoted by the Fe(II)-EDTA cleavage reagent (see below).

\section{Free radical scavengers}

Three broad classes of compounds that are routinely used in RNA preparations are known to inhibit strand scission by Fe(II)-EDTA. (1) Polyribose compounds, like bulk RNA and glycogen, are frequently used as carrier agents to coprecipitate end-labeled RNA species from ethanol. These compounds do not ordinarily pose a significant liability for most biochemical reactions involving RNA; however, they act as direct competitive inhibitors to strand scission by $\mathrm{Fe}$ (II)-EDTA since they contain the same highly reactive ribose moieties found in the end-labeled RNA. RNA transcripts can be precipitated from ethanolic solutions that contain low concentrations of simple salts, like $0.25 \mathrm{M}$ $\mathrm{NaCl}$ or $0.30 \mathrm{M} \mathrm{NaOAc}$, as one alternate precipitation procedure. (2) Glycerol, a cryoprotectant found in most protein storage buffers, is another efficient scavenger of free radicals. Glycerol is such an effective quencher of the Fe(II)-EDTA reaction that it can be used in place of thiourea (Latham and Cech, 1989). Glycerol is usually included in storage buffers to promote long-term stability of RNA-binding proteins, yet proteins often remain stable under short-term conditions with either no glycerol or low concentrations of glycerol present. One should evaluate whether the optimal reaction conditions require the presence of glycerol for studies that involve RNA-binding proteins. In the worst-case scenario, one may be able to empirically determine a low final concentration of glycerol that can be used to maintain the RNA-binding protein's biochemical activity and to allow for optimal strand scission by Fe(II)-EDTA generated free radicals. (3) Buffers that are enriched with primary alcohols, e.g., Tris, are effective free-radical scavengers since they more readily undergo hydrogen-atom abstraction than other buffering compounds. One should reduce the concentration of such buffers in solution or replace them with an alternative buffering component (e.g., MOPS) so that efficient RNA strand scission occurs (Celander and Cech, 1990).

\section{$\mathrm{Fe}(\mathrm{II})$-EDTA cleavage reagent freshness}

The most important ingredient to success in the strand-scission reaction is the use of fresh Fe(II)-EDTA and reducing agents. A common mistake made by those who cannot generate a decent cleavage pattern with end-labeled RNA is that the Fe(II)-EDTA reagent was prepared well before use (an hour or longer) or that old solutions of DTT or ascorbate were stored frozen from use in cleavage reactions performed at an earlier date. An Fe(II)-EDTA solution will undergo rapid oxidation to Fe(III)-EDTA, resulting in a yellow-colored solution in $<1 \mathrm{hr}$ after preparation. A fresh Fe(II)-EDTA solution should have a colorless to faint-blue tint, and such solutions are best prepared immediately before use. The chosen reducing reagent should
Chemical and Enzymatic Probes for Nucleic Acid Structure 
also be prepared immediately before use and discarded thereafter.

\section{Anticipated Results}

The interpretation of cleavage pattern on denaturing polyacrylamide gels is extremely straightforward. The cleavage pattern will be a fairly uniform banding pattern at each nucleotide position. The extent of cleavage varies little between reactions; most reactions generate $10 \%$ to $20 \%$ cleavage products. Since strand scission occurs with the loss of the ribose moiety for the affected nucleotide, the position at which the end-labeled RNA fragment migrates relative to sequencing standards is shifted by one nucleotide. For example, hydrogen atom abstraction at the ribose group of the seventeenth nucleotide in a $5^{\prime}$-[ $\left.{ }^{32} \mathrm{P}\right]$-end-labeled RNA chain will generate an oxidative strandscission product that migrates like an end-labeled 16-mer. The usual controls should be included to ensure that the cleavage pattern obtained is correctly attributed to the $\mathrm{Fe}$ (II)EDTA reagent rather than to an adventitious cleavage event caused by another source.

\section{Time Considerations}

This assay is extremely rapid to perform and requires little technical expertise or prior experience. The preparation of the end-labeled RNA is more time consuming than any aspect of the $\mathrm{Fe}(\mathrm{II})$-EDTA cleavage protocols described herein. One can learn an enormous amount of structural information about a folded RNA molecule or its association with other ligands in the time it takes to conduct these reactions $(<2 \mathrm{hr}$ ) and perform gel electrophoresis ( 3 to 5 $\mathrm{hr})$.

\section{Literature Cited}

Cate, J.H., Gooding, A.R., Podell, E., Zhou, K., Golden, B.L., Kundrot, C.E., Cech, T.R., and Doudna, J.A. 1996. Crystal structure of a group I ribozyme domain: principles of RNA packing. Science 273:1678-1685.
Celander, D.W. and Cech, T.R. 1990. Iron(II)ethylenediaminetetraacetic acid catalyzed cleavage of RNA and DNA oligonucleotides: Similar reactivity toward single- and double-stranded forms. Biochemistry 29:1355-1361.

Celander, D.W. and Cech, T.R. 1991. Visualizing the higher order folding of a catalytic RNA molecule. Science 251:401-407.

Darsillo, P. and Huber, P.W. 1991. The use of chemical nucleases to analyze RNA-protein interactions. The TFIIIA-5 S rRNA complex. J. Biol. Chem. 266:21075-21082.

Hertzberg, R.P. and Dervan, P.B. 1984. Cleavage of DNA with methidiumpropyl-EDTA-iron(II): Reaction conditions and product analyses. Biochemistry 23:3934-3945.

Heuer, T.S., Chandry, P.S., Belfort, M., Celander, D.W., and Cech, T.R. 1991. Folding of group I introns from bacteriophage T4 involves internalization of the catalytic core. Proc. Natl. Acad. Sci. U.S.A. 88:11105-11109.

Latham, J.A. and Cech, T.R. 1989. Defining the inside and outside of a catalytic RNA molecule. Science 245:276-282.

Pan, T. 1995. Higher order folding and domain analysis of the ribozyme from Bacillus subtilis ribonuclease P. Biochemistry 34:902-909.

Rosenstein, S.P. and Been, M.D. 1996. Hepatitis delta virus ribozymes fold to generate a solventinaccessible core with essential nucleotides near the cleavage site phosphate. Biochemistry 35:11403-11413.

Sclavi, B., Woodson, S., Sullivan, M., Chance, M.R., and Brenowitz, M. 1997. Time-resolved synchrotron X-ray "footprinting", a new approach to the study of nucleic acid structure and function: Application to protein-DNA interactions and RNA folding. J. Mol. Biol. 266:144-159.

Sclavi, B., Sullivan, M., Chance, M.R., Brenowitz, M., and Woodson, S.A. 1998. RNA folding at millisecond intervals by synchrotron hydroxyl radical footprinting. Science 279:1940-1943.

Westhof, E., Wesolowski, D., and Altman, S. 1996. Mapping in three dimensions of regions in a catalytic RNA protected from attack by an Fe(II)-EDTA reagent. J. Mol. Biol. 258:600-613.

Contributed by Daniel W. Celander

Loyola University Chicago

Chicago, Illinois
Probing RNA Structures with Hydroxyl Radicals 